\title{
Seizure Attacks While Driving: Quality of Life in Persons with Epilepsy
}

\author{
Somsak Tiamkao, Kittisak Sawanyawisuth, Somchai Towanabut, Pongsak \\ Visudhipun, Thai QOL Epilepsy Investigators
}

\begin{abstract}
Objective: To study the effect on quality of life (QOL) of a seizure attack while driving in persons with epilepsy (PWE). Methods: From four provincial and eight university hospitals in Thailand, we enrolled epileptic patients who drove a car or motorcycle or used to drive. The SF-36 questionnaire was used to evaluate QOL. The mean SF-36 score for all dimensions was calculated and compared with patients who either had or did not have a seizure attack while driving and in those who either had or had not been involved in a traffic accident while driving. Results: We had 245 adult PWE who drove a car or motorcycle or used to drive. Of these, 69 cases $(28 \%)$ had a seizure attack whilst driving. Over half $(36 / 69 ; 57 \%)$ had had seizure-related accidents, most of which were mild but about $20 \%$ needed hospitalization. PWE having a seizure attack while driving had a significantly lower QOL in four of the eight categories compared with patients who had not. PWE who had a seizure-related accident had a significantly lower mean value in the vitality category than those who did not. Conclusions: Seizure attacks while driving diminished QOL in PWE even though they only suffered minor injuries. Driving as a QOL issue should be discussed with patients. A good public transportation system would ease the need to drive.
\end{abstract}

RÉSUMÉ: Crises convulsives survenant pendant la conduite automobile et qualité de vie des personnes atteintes d'épilepsie. Objectif : Le but de l'étude était d'évaluer l'effet sur la qualité de vie (QV) de crises convulsives survenues pendant la conduite automobile chez des patients épileptiques (PÉ). Méthodes : Nous avons inclus dans l'étude des PÉ qui conduisaient une automobile ou une motocyclette ou qui en avaient conduit une dans le passé, identifiés dans quatre hôpitaux provinciaux et huit hôpitaux universitaires en Thaïlande. La QV a été évaluée au moyen du questionnaire SF-36. Le score moyen SF-36 pour toutes les dimensions a été calculé et comparé entre les patients qui avaient eu une crise en conduisant et ceux qui n'en avaient pas eu, et ceux qui avaient été impliqués dans un accident de la route en conduisant et ceux qui ne l'avaient pas été. Résultats : Nous avons identifié 245 PÉ adultes qui conduisaient une automobile ou une motocyclette ou qui en avaient conduit une dans le passé. Parmi eux, 69 patients (28\%) ont eu une crise alors qu'ils conduisaient. Plus de la moitié $(36 / 69 ; 57 \%)$ avaient eu des accidents en rapport avec une crise, dont la plupart étaient mineure. Cependant, environ $20 \%$ ont dû être hospitalisés. Les PÉ qui avaient eu une crise alors qu'ils conduisaient avaient une QV significativement plus faible dans quatre des huit catégories par rapport aux patients qui n'en avaient pas eu. Les PÉ qui avaient eu un accident en rapport avec une crise avaient une valeur moyenne significativement plus faible dans la catégorie vitalité que ceux qui n'en avaient pas eu. Conclusions : Les crises épileptiques survenues en conduisant diminuent la QV chez les PÉ même s'ils ne subissent que des blessures légères. L'aspect QV de la conduite devrait être abordé avec les patients. Un bon service de transport en commun peut diminuer le besoin de conduire.

Can. J. Neurol. Sci. 2009; 36: 475-479

Epilepsy is known to reduce the quality of life (QOL). Seizure frequency is negatively associated with all the shortform health questionnaire survey (SF-36) categories. ${ }^{1}$ Daily use of benzodiazepines, depressive symptoms, comorbid psychiatric conditions, being female and employability are strong predictors of a poor QOL in persons with epilepsy (PWE). Older PWE appear to adapt better to their chronic health problem. ${ }^{2}$

Persons with epilepsy also have some restrictions in some areas of life such as recreational activities, social situations, employment and driving. ${ }^{3}$ Permission to drive may depend on the normal seizure free period and physical fitness of each applicant. ${ }^{4}$ Any driving restriction significantly relates to independence, employment and QOL.

Driving allowance for PWE is different in each country. ${ }^{5}$ In Thailand, there is no legal driving restriction for persons subject to active seizures, although patients are encouraged to refrain from driving until the seizures are under control. ${ }^{6}$ A mandatory reporting of epilepsy or other medical conditions by physicians to government is still debated.

From the Department of Medicine (ST, KS), Faculty of Medicine, Khon Kaen University, Khon Kaen; Department of Neurology (ST), Prasart Neurological Institute; Department of Pediatrics (PV), Faculty of Medicine, Ramathibodi, Mahidol University, Bangkok; The Epilepsy Society of Thailand (Thai QOL Epilepsy investigators), Bangkok, Thailand.

Received November 7, 2008. Final Revisions Submitted March 2, 2009. Correspondence to: Somsak Tiamkao, Division of Neurology, Department of Medicine, Faculty of Medicine, 123 Mitraparp Road, Srinagarind Hospital, Khon Kaen University, Khon Kaen, 40002, Thailand. 
Being allowed to drive is important for employment ${ }^{7}$ and QOL. However, if seizures occur while driving, injury may result to the driver, passengers, other vehicles and their passengers, property and bystanders. We studied seizure attacks while driving and its affect on quality of life. To our knowledge, the effect, as measured on the SF-36, of PWEs having a motor vehicle accident because of a seizure has not been reported.

\section{MethoDS}

We studied adult PWE who used to drive or currently drive and were being treated for epilepsy in one of four selected provincial and eight university hospitals in Thailand. Eligible patients provided written informed consent and the study's protocol was approved by the institutional review board at each center.

A self-reported questionnaire was used to evaluate each participant's baseline characteristics and QOL. The data comprised demographic data, history of seizure attack while driving and history of traffic accidents related to seizure attacks. We evaluated the QOL using the Thai version of the SF-36 that has been shown to be reliable and valid. ${ }^{8,9}$ The SF-36 assesses eight dimensions including physical functioning, physical role, bodily pain, general health, vitality, social functioning, emotional role and mental health. ${ }^{10}$ The first four dimensions are considered physical components and the latter four mental. The potential score range is $0-100-100$ indicating the best health in that dimension.
The definition of each dimension follows. Physical functioning is the ability to perform all types of physical activities including the most vigorous without limitation due to health. The physical role is the extent to which physical problems interfere with usual daily activities such as work/chores, household or school. Bodily pain is the extent of bodily pain or limitation due to pain. General health is the rating of current health in general. Vitality is a rating of energy level. Social functioning is the ability to perform normal social activities without interference due to physical or emotional problems. Emotional role is the extent to which emotional problems interfere with usual daily activities such as work, household or school. Mental health is the rating of current mental health status in general.

\section{Data analyses}

We categorized the eligible patients into two groups by history of seizure attack while driving (yes/no) and seizurerelated injury while driving (yes/no). The independent student ttest and Chi-square or Fisher Exact test were used to compare differences in means and proportions, respectively, of the two groups. A difference was considered significant if $\mathrm{p}<0.05$.

The mean SF-36 score for all categories was calculated and compared between patients who had or did not have a seizure attack while driving and between those who had or did not have a traffic accident. The Student t-test was used to examine the difference in categories between groups. Statistical significance

Table 1: Characteristics of persons with epilepsy who had and did not have a seizure attack while driving

\begin{tabular}{|c|c|c|c|c|}
\hline Variables & $\begin{array}{l}\text { Seizure attack } \\
(\mathrm{N}=69) \\
\text { Group A }\end{array}$ & $\begin{array}{l}\text { No seizure } \\
\text { attack } \\
(\mathrm{N}=176) \\
\text { Group B } \\
\end{array}$ & $\begin{array}{l}\mathrm{t} / \mathrm{F} / \mathrm{Chi} \\
\text { square } \\
\text { value }\end{array}$ & $\mathrm{p}$ value \\
\hline Mean age (SD) & $35.12(11.31)$ & $32.30(13.25)$ & 1.94 & 0.053 \\
\hline Mean age of epilepsy onset (SD) & $21.37(13.26)$ & $22.08(14.76)$ & -0.34 & 0.734 \\
\hline Mean duration of epilepsy (SD) & $15.06(11.02)$ & $10.47(9.31)$ & 3.29 & 0.001 \\
\hline Males, N (\%) & $51(73.91)$ & $93(52.84)$ & 9.08 & 0.003 \\
\hline Marital status, N (\%) & & & 0.02 & 0.332 \\
\hline Single & $33(48.53)$ & $86(50.00)$ & & \\
\hline Married & $33(48.53)$ & $85(49.42)$ & & \\
\hline Divorced & $2(2.94)$ & $1(0.58)$ & & \\
\hline Education, N (\%) & & & 1.50 & 0.473 \\
\hline Primary school & $11(18.03)$ & $38(25.00)$ & & \\
\hline Secondary school & $28(48.90)$ & $69(45.39)$ & & \\
\hline College or higher & $22(36.07)$ & $45(29.61)$ & & \\
\hline Work status, N (\%) & & & 0.40 & 0.819 \\
\hline Full time & $39(62.90)$ & $85(61.59)$ & & \\
\hline Part time & $7(11.29)$ & $20(14.49)$ & & \\
\hline Unemployed & $16(25.81)$ & $33(23.91)$ & & \\
\hline Income, N (\%) & & & 0.99 & 0.321 \\
\hline$<350 \mathrm{CAD} /$ month & $36(52.94)$ & $99(60.00)$ & & \\
\hline$\geq 350 \mathrm{CAD} /$ month & $32(47.06)$ & $66(40.00)$ & & \\
\hline Region, N (\%) & & & 3.99 & 0.262 \\
\hline North & $14(20.29)$ & $36(20.45)$ & & \\
\hline Northeast & $20(28.99)$ & $62(35.23)$ & & \\
\hline South & $16(23.19)$ & $23(13.07)$ & & \\
\hline Central and Bangkok & $19(27.54)$ & $55(31.25)$ & & \\
\hline Frequency of seizure, $\mathrm{N}(\%)$ & & & 22.36 & $<0.001$ \\
\hline None & $12(17.65)$ & $64(36.78)$ & & \\
\hline $1-12$ times/year & $28(41.18)$ & $85(48.85)$ & & \\
\hline zonce/month & $28(41.18)$ & $25(14.37)$ & & \\
\hline
\end{tabular}

Note: Data for the seizure attack and no seizure attack group may not total 69 and 176, respectively, because of missing data. SD; standard deviation, N; number of subjects, F; Fisher exact probability 
Table 2: Driving information and their perception according to the questionnaire

\begin{tabular}{|c|c|c|c|c|}
\hline Variables & $\begin{array}{l}\text { Seizure attack } \\
(\mathrm{N}=69) \\
\text { Group A }\end{array}$ & $\begin{array}{l}\text { No seizure } \\
\text { attack } \\
(\mathrm{N}=176) \\
\text { Group B }\end{array}$ & $\begin{array}{l}\text { F/Chi square } \\
\text { value }\end{array}$ & $\mathrm{p}$ value \\
\hline Seizure controllable & & & 0.04 & 0.833 \\
\hline Yes & $37(53.62)$ & $79(44.89)$ & & \\
\hline No & $32(46.38)$ & $97(55.11)$ & & \\
\hline Satisfaction with treatment & & & $<0.01$ & 0.002 \\
\hline Yes & $61(88.41)$ & $161(92.00)$ & & \\
\hline Neutral & $2(2.90)$ & $13(7.43)$ & & \\
\hline No & $6(8.70)$ & $1(0.57)$ & & \\
\hline Driving prior to diagnosis & & & 6.54 & 0.011 \\
\hline Yes & $54(78.26)$ & $103(60.95)$ & & \\
\hline No & $15(21.74)$ & $66(39.05)$ & & \\
\hline Driving after the diagnosis & & & 0.33 & 0.568 \\
\hline Yes & $62(89.86)$ & $150(87.21)$ & & \\
\hline No & $7(10.14)$ & $22(12.79)$ & & \\
\hline Driving status prior-after the diagnosis & & & 6.08 & 0.108 \\
\hline Yes to Yes & $51(73.91)$ & $98(58.68)$ & & \\
\hline Yes to No & $3(4.35)$ & $5(2.99)$ & & \\
\hline No to Yes & $11(15.94)$ & $48(28.74)$ & & \\
\hline No to No & $4(5.80)$ & $16(9.58)$ & & \\
\hline Type of vehicle & & & 0.15 & 0.703 \\
\hline Motorcycle & $39(73.58)$ & $109(76.22)$ & & \\
\hline Car & $14(26.42)$ & $34(23.78)$ & & \\
\hline Frequency of driving & & & 1.37 & 0.505 \\
\hline Everyday & $40(60.61)$ & $114(67.06)$ & & \\
\hline$\geq 3$ times/week & $16(24.24)$ & $30(17.65)$ & & \\
\hline$<3$ times/week & $10(15.15)$ & $26(15.29)$ & & \\
\hline
\end{tabular}

Note: Data for seizure attack and no seizure attack group may not total 69 and 176, respectively, because of missing data. N (\%); number of subjects (Percent), F; Fisher exact probability

required a $\mathrm{p}$ value $<0.05$. Data were analyzed using SPSS version 11.5 (SPSS, Inc., Chicago, IL).

\section{Results}

There were 245 adult PWE who drove a car or motorcycle or used to. Of those, 69 subjects $(28.1 \%)$ had had a seizure attack while driving (Group A). The patients in Group A had more men and were older than the group that had not had a seizure attack while driving (Group B). The subjects in Group A had had a longer duration of epilepsy, a higher frequency of seizure attack and less satisfaction with treatment than Group B (Table 1).
The motorcycle to car ratio was $3: 1$. About $60 \%$ of the subjects had a daily driving schedule (Table 2). After being diagnosed with epilepsy, $73 \%$ of the subjects in Group A continued to drive, while only $28 \%$ of the subjects in Group B started driving after being diagnosed. Most subjects satisfied with the treatment; significantly higher numbers of subjects in Group B (Table 2).

The mean values for all eight dimensions of the SF-36 were lower in Group A. Half of the dimensions, in both the physical and mental aspects, were significantly different between groups; namely, physical role, general health, vitality and mental health: the first two being physical and the latter two mental components (Table 3).

Table 3: The short-form health questionnaire survey (SF-36) score for the eight dimensions for persons with epilepsy who had and did not have a seizure attack while driving

\begin{tabular}{lllll}
\hline SF-36 dimension & $\begin{array}{l}\text { Seizure attack (mean } \\
\pm \mathrm{SD})\end{array}$ & $\begin{array}{l}\text { No seizure attack } \\
\mathrm{N}=69\end{array}$ & $\mathrm{t}$ value & $\mathrm{p}$ value \\
& $87.25 \pm 16.46$ & $88.76 \pm 13.75$ & -0.73 & 0.469 \\
\hline Physical functioning & $63.77 \pm 38.24$ & $77.98 \pm 33.40$ & -2.87 & 0.004 \\
Physical role & $70.94 \pm 24.75$ & $75.95 \pm 21.13$ & -1.59 & 0.114 \\
Bodily pain & $49.19 \pm 22.67$ & $57.95 \pm 22.72$ & -2.68 & 0.008 \\
General health & $57.35 \pm 17.98$ & $63.72 \pm 20.28$ & -2.24 & 0.026 \\
Vitality & $70.96 \pm 21.86$ & $74.93 \pm 22.32$ & -1.25 & 0.213 \\
Social functioning & $62.32 \pm 40.79$ & $70.48 \pm 38.30$ & -1.47 & 0.143 \\
Emotional role & $59.70 \pm 17.74$ & $68.09 \pm 18.14$ & -3.22 & 0.001 \\
Mental health & & & & \\
\hline
\end{tabular}

Note: Data for seizure attack and no seizure attack group may not total 69 and 176, respectively, because of missing data. 


\begin{abstract}
Table 4: The short-form health questionnaire survey (SF-36) score for all eight dimensions for persons with epilepsy who had and did not have injuries from a
\end{abstract} seizure-related accident

\begin{tabular}{lllll}
\hline SF-36 dimension & $\begin{array}{l}\text { Injured } \\
(\text { mean } \pm \mathrm{SD})\end{array}$ & $\begin{array}{l}\text { Not injured } \\
(\text { mean } \pm \mathrm{SD})\end{array}$ & t value & $\mathrm{p}$ value \\
& $\mathrm{N}=39$ & $\mathrm{~N}=30$ & \\
\hline Physical functioning & $86.28 \pm 14.81$ & $88.50 \pm 18.58$ & -0.55 & 0.583 \\
Physical role & $57.69 \pm 39.80$ & $71.67 \pm 35.19$ & -1.52 & 0.133 \\
Bodily pain & $67.69 \pm 28.54$ & $75.17 \pm 18.35$ & -1.32 & 0.192 \\
General health & $47.23 \pm 23.49$ & $51.83 \pm 21.63$ & -0.83 & 0.412 \\
Vitality & $53.72 \pm 17.69$ & $62.59 \pm 17.40$ & -2.02 & 0.048 \\
Social functioning & $68.59 \pm 22.37$ & $74.14 \pm 21.11$ & -1.04 & 0.304 \\
Emotional role & $58.97 \pm 41.51$ & $66.67 \pm 40.12$ & -0.77 & 0.442 \\
Mental health & $59.49 \pm 18.72$ & $60.00 \pm 16.57$ & -0.11 & 0.907 \\
\hline
\end{tabular}

Note: Data for injured and not injured group may not total 39 and 30, respectively, because of missing data.

Thirty-nine of 69 cases $(57 \%)$ had had a seizure-related accident(s). Accidents caused injury to the driver in $26.3 \%$ of the cases and to the passenger in $8.3 \%$. Most accidents were not severe with an ER admission rate of $22.4 \%$ and $13.4 \%$ among drivers and passengers, respectively. There was one seizurerelated passenger death.

The mean SF-36 scores were lower among patients who had had a seizure-related accident(s) than those who did not. Patients who had a seizure-related accident had a significantly lower mean value for vitality than those who did not (Table 4).

\section{Discussion}

This is the first study showing a lower QOL in PWE with seizure attack while driving. These patients had a significantly lower QOL score for their physical role, general health, vitality and mental health. Chronic neurological disorders such as epilepsy have a direct effect on mental health. ${ }^{11}$ Our results show that if a seizure attack occurs while driving, it likely affects more than just mental health. Indeed, our findings suggest an overall poorer physical and mental QOL if the PWE had a seizure while driving. The driving issue for PWE in clinical practice needs to be considered.

It has been demonstrated that the rate of traffic accidents for PWE is not different from the general population; ${ }^{12}$ however, permission to drive (licensing PWEs) is still being debated and varies from country to country. Concern over public safety has meant PWE have not been allowed to drive and sometimes not even granted driving licenses. ${ }^{13}$ The contribution of epilepsy to fatal road accidents in Europe is not clear. ${ }^{14}$ In 1991, 0.025$0.053 \%$ of all traffic accidents in Australia were caused by epilepsy. ${ }^{14}$ A population-based study in the USA showed that seizures caused 86 deaths per annum or $0.2 \%$ of all traffic deaths. ${ }^{15}$

From our results, almost $30 \%$ of our patients had a seizure attack while driving. Of those, the seizure-related accident rate was $57 \%$. Even though only about $20 \%$ needed admission to
Emergency, there was one passenger death. Compared to previous studies ${ }^{16,17}$, our study had a higher prevalence of accidents among PWEs but with less severity.

According to overall road accident statistics, all drivers in Thailand have a higher chance of accidents. Persons with epilepsy, however, may have an even higher risk because there are no legal restrictions to PWEs driving in Thailand, whereas in the EU, USA, UK or Canada there are specific laws in place limiting licensing of epileptics. These findings may be explained by the fact that there is no driving law enforcement for PWEs in Thailand and that the most common vehicles on the road are motorcycles. Relatedly, Van der Lugt reported that $96 \%$ of epileptic drivers involved in accidents had not previously reported their epilepsy in applying for a driver's license. ${ }^{18}$ If patients provide incomplete/incorrect information regarding seizure control and activities, the evaluating physician might make an incorrect decision and approve licensing eligibility. Accurate information concerning seizure activity is of critical importance.

Considering PWEs who had seizure-related accidents, those with injuries had a significantly lower vitality score than those who did not. This result suggests that physical illnesses from the accident(s) negatively affected mental function. Generally, the mean score for each dimension among PWEs with seizurerelated injuries was lower than it was for those who did not have any associated injuries.

Both physical and mental aspects of the quality of life were significantly lower in persons with epilepsy who drive, particularly when seizures occur while driving; irrespective of the severity of the accident(s). Driving as a QOL issue should be discussed thoroughly with PWEs, both to prepare them and to help them to consider the risks and possible alternatives.

\section{ACKNOWLEDGEMENTS}

The authors thank the participating patients and support staff at the epilepsy clinics who helped with our study. We thank 
Sanofi-aventis, Thailand for grant support and Mr. Bryan Roderick Hamman for assistance with the English-language presentation of the manuscript.

\section{Thai QOL Epilespy Investigators}

Suthida Yenjun, Kanlaya Dhiravibulya, Apasri Lusawat, Suwannee Phancharoen, Rungsan Chaisewikul, Anannit Visudtibhan, Yotin Chinvarun, Charcrin Nabangchang, Malai Panichapong, Araya Charuvanij, Sahas Liamsuwan, Kanokwan Watcharasaksilp, Surachai Likasitwattanakul, Arkhom Arayawichanont, Penchan Saipan, Suwanna Setthawatcharawanich, Kongkiat Kulkantrakorn, Sasitorn Sirimaharaj, Praphan Yodnopklow, Thanin Asawavichienjinda, Punnee Vasiknanonte

\section{REFERENCES}

1. Leidy NK, Elixhauser A, Vickrey B, Means E, Willian MK. Seizure frequency and the health-related quality of life of adults with epilepsy. Neurology. 1999; 53: 162-6.

2. Mosaku KS, Fatoye FO, Komolafe M, Lawal M, Ola BA. Quality of life and associated factors among adults with epilepsy in Nigeria. Int J Psychiatry Med. 2006; 36: 469-81.

3. Drazkowski JF. Management of the social consequences of seizures. Mayo Clin Proc. 2003; 78: 641-9.

4. Drazkowski JF. An overview of epilepsy and driving. Epilepsia. 2007; 48: 10-2.

5. Krauss GL, Ampaw L, Krumholz A. Individual state driving restrictions for people with epilepsy in the US. Neurology. 2001; 57: $1780-5$

6. Locharernkul C. Epilepsy and the law--a view from Thailand. J Med Assoc Thai. 2007; 90: 587-98.

7. Polychronopoulos P, Argyriou AA, Huliara V, Sirrou V, Gourzis P, Chroni E. Factors associated with poor compliance of patients with epilepsy driving restriction. Neurology. 2006; 67: 869-71.
8. Setthawatcharawanich S, Aui-aree N, Limapichart K, Satirapunya $P$, Phabphal K. The validation of the disease-specific questionnaire for health-related quality of life in Thai patients with hemifacial spasm. J Med Assoc Thai. 2008; 91: 1691-7.

9. Lim LL, Seubsman SA, Sleigh A. Thai SF-36 survey: tests of data quality, scaling assumptions, reliability and validity in healthy men and women. Health Qual Life Outcomes. 2008; 6: 52.

10. Garratt AM, Ruta DA, Abdalla MI, Buckingham JK, Russell IT. The SF-36® Health Survey Questionnaire: an outcome measure suitable for routine use within the NHS? Br Med J. 1993; 306: 1440-4.

11. Hermann BP, Vickrey B, Hays RD, Cramer J, Devinski O, Meador $\mathrm{K}$, et al. A comparison of health-related quality of life in patients with epilepsy, diabetes and multiple sclerosis. Epilepsy Res. 1996; 25: 113-8.

12. Taylor J, Chadwick D, Johnsons T. Risk of accidents in drivers with epilepsy. J Neurol Neurosurg Psychiatry. 1996; 60: 612-7.

13. Krumholz A. Driving and epilepsy: a historical perspective and review of current regulations. Epilepsia. 1994; 35: 668-74.

14. A report of the second European Working Group on Epilepsy and Driving. April 2005. Available from http://ec.europa.eu/ transport/roadsafety/behavior/doc/epilepsy_and_driving_in_eur ope_final_report_v2_en.pdf.

15. Sheth SG, Krauss G, Krumholz A, Li G. Mortality in epilepsy: driving fatalities vs other causes of death in patients with epilepsy. Neurology. 2004; 63: 1002-7.

16. Sapna CS, Sheeba SL, John J, Thomas SV. Epilepsy and driving capability in Slovenia. Epileptic Disord. 2008; 10: 276-81.

17. Bilban M. Accidents and injuries in people with epilepsy attending a tertiary care center in India. Seizure. 2008; 17: 465-8.

18. Van der Lugt PJ. Traffic accidents caused by epilepsy. Epilepsia. 1975; 16: 747-51. 